\title{
Impact of Intervention on Maternal and Child Health Knowledge of Farm Mothers
}

\author{
Nasreen Banu ${ }^{1 *}$ and K. Yashoda ${ }^{2}$
}

${ }^{1}$ AICRP-H.Sc (All India Coordinated Research Project-Home Science), PGRC, PJTSAU (Professor Jayashankar Telangana State Agricultural University), Rajendranagar, Hyderabad - 30, Telangana State, India

${ }^{2}$ AICRP-H.Sc, PGRC, PJTSAU, Rajendranagar, Hyderabad - 30, India

*Corresponding author

\section{A B S T R A C T}

\begin{tabular}{|l|}
\hline Ke y w o r d s \\
Maternal \& Child \\
health, Intervention \\
programme, \\
Knowledge
\end{tabular}

\section{Introduction}

Despite a number of global and national efforts to improve women's health, death of women during child birth remains an unresolved challenge in many developing countries. Some estimates indicate that at least half million women die from pregnancy related causes (WHO/UNICEF/UNFPA/The World Bank, 2007). The estimates further show that $99 \%$ of these deaths occur in developing countries, especially in subSaharan Africa and there is slower pace in reducing maternal mortality compared to other regions of the world from 1990 to 2005 . While the overall the global decline in maternal mortality ratio between 1990 and 2005 was $5.4 \%$, the annual decline was less than $1 \%$.

Most of maternal deaths are caused by factors attributed to pregnancy, childbirth and poor quality of health services. About $60 \%$ of maternal deaths occur during labour, delivery and immediate post-partum period. Fifty percent of these deaths occur within the first 24 hours of delivery (Koblinky, 2003; Campbell et al., 2006). Comparatively, a woman in East Africa has 1 in 12 risk of dying 
due to pregnancy as compared to 1 in 4,000 in northern Europe (FHI, 2007). Most complications cannot be predicted; therefore timely diagnosis with skilled personnel is important to avoid introducing harm (Campbell et al., 2006).

Maternal mortalities are caused by different factors which can be categorized as direct, indirect and underlying causes. The major direct causes include obstetric hemorrhage, obstructed labour, pregnancy induced hypertension, sepsis and abortion complications (Urassa et al., 1995; Abou Zahr, 1995; WHO, 2010). The direct causes are related to obstetric complications and contribute to three quarters of maternal deaths (Starr, 1997). Poor access to reproductive service increases risks of getting unwanted pregnancies. Teenagers in Africa account for about $20 \%$ of maternal deaths and most are due to unsafe abortion (Rogo et al., 2006).

Despite the current increasing indirect causes of maternal death as a result of HIV/AIDS pandemic, still the majority of deaths are due to direct obstetric causes. Maternal death due to the direct causes can be prevented if timely access to appropriate emergency obstetric care is availed. But maternal deaths only tell part of the story. For instance, it is acknowledged that for every woman who dies as a result of pregnancy-related causes, between 20 and 30 more women will develop short- and longterm disabilities, such as obstetric fistula, a ruptured uterus, or pelvic inflammatory disease (Waldijk, 1994). Such morbidities impacts on the active labour force necessary for eradication of poverty in developing countries, not only of the family but also the community who have to care for the children and/or the disabled women at the expense of economic activities necessary for their livelihoods.

\section{Operational definition}

\section{Knowledge}

Knowledge is a familiarity, awareness, or understanding of someone or something, such as facts, information, descriptions, or skills, which is acquired through experience or education by perceiving, discovering, or learning.

According to Webster's dictionary, knowledge is 'the fact or condition of knowing something with familiarity gained through experience or association'. In practice, though, there are many possible, equally plausible definitions of knowledge. A frequently used definition of knowledge is "the ideas or understandings which an entity possesses that are used to take effective action to achieve the entity's goal(s).

\section{Intervention}

An intervention is a combination of programme elements or strategies designed to produce behavior changes or improve health status among individuals or an entire population.

\section{Maternal health}

It refers to the health of women during pregnancy, childbirth and the postpartum period.

\section{Child health}

It is a state of physical, mental, intellectual, social and emotional well-being and not merely the absence of disease or infirmity.

Healthy children live in families, environments, and communities that provide them with the opportunity to reach their fullest developmental potential. 


\section{Materials and Methods}

Sample was identified from the adopted villages (5) of Maheshwarammandal, RR District, Hyderabad, through field survey and focused group interviews with the help of the AWWs, ANMs, and Women Self-help Group leaders in the village.

\section{Criteria for sample selection}

- Women who were married and living with their husband

-

- Women who were married and having children between 2-5 years

\section{General objective}

Promoting Maternal \& Child health Knowledge among Rural mothers

\section{Specific objectives}

To find out the demographic profiles of the Selected sample

To find out the Knowledge levels of the Selected sample with regard to Maternal \& Child health

To develop suitable IEC material for promoting Maternal \& Child health among the selected sample

To conduct Knowledge based Intervention programme to the selected sample

To assess the impact of Intervention programme on the Knowledge levels of the selected sample

\section{Research strategy adopted}

In order to achieve the above objectives, Knowledge based Intervention programmes (20) were organized for the Rural mothers with children between 2-5 years, using the developed IEC material.

\section{Research tools details}

SES scale developed by Aggrawal et al., (2005) was used to find out the SES of the Rural families. Scoring was given as per the norms provided in the manual. It is a standardized scale, used to assess the family background information of the individuals, which includes parameters like educational and occupational status of parents, number of siblings, material possession, kind of locality, presence of farm animals, land holdings, number of earning members in the family etc. The scale categorizes the sample on: Upper High; High; Upper middle; Lower middle; Poor and Very poor Socio Economic Status.

Maternal \& Child Health awareness checklist was developed by AICRP-CD, Hyd Unit (2017) to find out the Knowledge levels of Married women with regard to Maternal \& Child Health issues. The Reliability Value of the checklist is: 0.85 . The checklist comprises of 3 dimensions:

Pregnancy related statements: It is the First dimension and has 48 statements. It measures the knowledge levels of the sample in the following 7 areas: Signs of Pregnancy (7 statements); Care during Pregnancy (9 statements); Factors affecting healthy pregnancy (6 statements); Health aspects of pregnancy (5 statements); Danger signs of pregnancy (11 statements); Complications that may arise during pregnancy (6 statements); Types of Delivery (4 statements).

Maternal \& child services and programmes: It is the Second dimension and has 33 statements. It measures the knowledge levels of the sample in the following 6 areas: Reproductive \& child health programmes (5statements); Purpose of R \& $\mathrm{CH}$ programmes (6 statements); Antenatal care 
services (5 statements); Purpose of Antenatal care services (8 statements); Post-natal care services (5 statements) Purpose of Postnatal care services (4 statements).

General statements: It is the Third dimension and has 13 statements. It measures the knowledge levels of the sample in the following 3 areas: Practices that jeopardize infant health, growth or survival (4statements); Care of the new born (3statements); Nutritional care of the child (6statements).

There are all together 94 statements (all 3 dimensions). Each statement is arranged on 3 point scale i.e., aware is marked as 3; aware but not sure 2; Not sure as 1 . The total scores were further grouped as Low, Average and high. Higher the score, higher is the level of Knowledge in that particular dimension.

\section{Results and Discussion}

\section{Demographic data on married women}

There were 961 married women from the selected clusters of adopted villages, Maheshwarammandal, RR district. Out of 961 married women, 37\% (357) were having children between 2-5 years and 75 formed the sample for the present study.

The table 1 depicts the Age wise distribution of Rural mothers with children (between 2 -5 years). Out of the total sample 75 , less than half of (44\%) were in the age range of 26-30 yrs; $33 \%$ were in the age group of 20-25 yrs and the remaining $23 \%$ were in the age group of 31-35 yrs.

The table 2 depicts the Education wise distribution of Rural mothers with children (between $2-5$ years). Out of the total sample 75 , thirty six percent of the sample completed Secondary school; $31 \%$ completed Inter; $22 \%$ completed Primary school; $7 \%$ were illiterates and only $4 \%$ were pursuing their degree. The table 3 depicts the Occupation wise distribution of Rural mothers with children (between $2-5$ years). Out of the total sample 75 , forty four percent of the sample were fully involved in agriculture; $37 \%$ were partially involved in agriculture; $12 \% \%$ were housewives; and only $7 \%$ were running petit business.

The table 4 depicts the Socio Economic Status of Rural mothers with children (between 2 - 5 years). Out of the total sample 75, more than half of $(60 \%)$ the sample were in lower middle income level; $20 \%$ were in poor economic status; $17 \%$ were in upper middle income level and only $3 \%$ were in high income group.

The table 5 traces the pretest scores of married women with regard to Maternal Health \& Child care Knowledge / practices. The Self structured Checklist covers 3 dimensions.

With regard to Pregnancy dimension, out of 75 sample more than half $(53 \%)$ of the sample obtained Average scores; 31\% obtained High scores and $16 \%$ obtained Low scores.

With regard to Maternal \& Child Services \&Programmes dimension, out of 75 sample more than half $(56 \%)$ of the sample obtained Average scores; $31 \%$ obtained High scores and $13 \%$ obtained Low scores.

With regard to General dimension, out of 75 sample less than half $(49 \%)$ of the sample obtained Average scores; 35\% obtained High scores and $16 \%$ obtained Low scores.

\section{Planning \& preparing educational material for conducting awareness programmes on issues concerning reproductive health care among rural mothers}

Based on the bench mark issues and preassessment results, videos, brochures, leaflets, 
resource books and educational posters were planned / developed on selected thematic areas.

Educational posters mainly focused on: Comprehensive nutrition; Condom use; Contraception choices; Healthy pregnancy; HIV prevention; Transmission of AIDs; Transmission of STI/ RTI; Reproductive rights; Reproductive problems; Reproductive health; Antenatal care; Immunization schedule; Menstrual hygiene; Menstrual problems; Menstrual education.

Videos mainly focused on: Importance of Reproductive Health; Antenatal Care; Reproductive rights; Menstrual problems; HIV prevention; Healthy pregnancy; Reproductive Health; Maternal \& Child health services; Personal Hygiene during periods; Sanitation of sanitary pads / Methods of disposing sanitary pads/cloth; Managing Malnutrition in Children

Booklets on: Healthy Pregnancy; Eating for Healthy Pregnancy; Newborn care; Reproductive health

Conducting programmes on Maternal\& Child health for the selected sample: Knowledge based Capacity building programmes (20) were conducted for married women from the adopted villages on issues concerning Maternal \& Child health. Some of the intervention strategies used for promoting Reproductive Health Knowledge among the sample was: group exercises, role plays, open ended stories, Brain storming, Group activities, Situation analysis, Case studies, Responding to real life situations and Group discussions etc.

\section{Impact of knowledge based intervention}

The table 6 traces the pretest scores of married women with regard to Maternal Health \& Child care Knowledge / practices. The Self structured Checklist covers 3 dimensions.

With regard to Pregnancy dimension, out of 75 sample more than half (59\%) of the sample obtained High scores; $37 \%$ obtained Average scores and only 4\%obtained Low scores.

With regard to Maternal \& Child Services \& Programmes dimension, out of 75 sample more than half $(56 \%)$ of the sample obtained High scores; $36 \%$ obtained Average scores and only $8 \%$ obtained Low scores.

With regard to General dimension, out of 75 sample more than half $(59 \%)$ of the sample obtained High scores; $37 \%$ obtained Average scores and only 4\%obtained Low scores.

Table.1 Age wise distribution of the selected sample $(\mathrm{N}=75)$

\begin{tabular}{|r|c|c|c|}
\hline $16-19$ yrs & $20-25$ yrs & $26-30 y r s$ & $31-35 y r s$ \\
\hline N \& \% & N \& \% & N \& \% & N \& \% \\
\hline----- & $25(33 \%)$ & $33(44 \%)$ & $17(23 \%)$ \\
\hline
\end{tabular}

Table.2 Education wise distribution of the selected sample $(\mathrm{N}=75)$

\begin{tabular}{|c|c|c|l|l|}
\hline Illiterate & Primary school & Secondary school & Inter & $\begin{array}{l}\text { Degree } \\
\text { Continuing }\end{array}$ \\
\hline N \& \% & N \& \% & N \& \% & N \& \% & N \& \% \\
\hline $\mathbf{5}(\mathbf{7 \%})$ & $17(22 \%)$ & $27(36 \%)$ & $23(31 \%)$ & $3(4 \%)$ \\
\hline
\end{tabular}


Table.4 Socio economic status of the sample $(\mathrm{N}=75)$

\begin{tabular}{|l|c|r|}
\hline $\begin{array}{l}\text { Socio economic status } \\
\text { classification }\end{array}$ & Score & $\begin{array}{l}\text { Rural mothers with } \\
\text { children between 2-5 yrs } \\
\text { (N=75) }\end{array}$ \\
\hline Upper High & $>76$ & $\mathbf{- - -}$ \\
\hline High & $61-75$ & $\mathbf{2 ( 3 \% )}$ \\
\hline Upper middle & $46-60$ & $\mathbf{1 3}(\mathbf{1 7 \%})$ \\
\hline Lower middle & $31-45$ & $\mathbf{4 5}(\mathbf{6 0 \%})$ \\
\hline Poor & $16-30$ & $\mathbf{1 5}(\mathbf{2 0 \%})$ \\
\hline Very poor & $<15$ & ---- \\
\hline
\end{tabular}

Table.5 Maternal and child health knowledge scores of rural mothers - pretest scores

\begin{tabular}{|l|l|l|l|r|}
\hline s.no & $\begin{array}{l}\text { Maternal \& child health } \\
\text { awareness dimensions }\end{array}$ & Category & Score & $\begin{array}{l}\text { Married women with children } \\
\text { between 2 - 5 yrs (N=75) No \& }\end{array}$ \\
\hline A & Pregnancy & High & $97-144$ & $23(31 \%)$ \\
\cline { 3 - 5 } & & Average & $49-96$ & $40(53 \%)$ \\
\hline \multirow{2}{*}{ B } & \multirow{2}{*}{$\begin{array}{l}\text { Maternal \& Child Services } \\
\text { \&programmes }\end{array}$} & High & $<48$ & $12(16 \%)$ \\
\hline & & Average & $34-66$ & $23(31 \%)$ \\
\hline C & \multirow{2}{*}{ General } & Low & $<33$ & $42(56 \%)$ \\
\hline & & High & $27-39$ & $10(13 \%)$ \\
\hline & & Average & $14-26$ & $26(35 \%)$ \\
\hline & Low & $<13$ & $37(49 \%)$ \\
\hline
\end{tabular}

Table.6 Maternal and child health knowledge scores of rural mothers (with children between 2-5 years) - post assessment scores

\begin{tabular}{|l|l|l|l|r|}
\hline s.no & $\begin{array}{l}\text { Maternal \& child health } \\
\text { awareness dimensions }\end{array}$ & Category & Score & $\begin{array}{l}\text { Married women with } \\
\text { children between 2 - 5 } \\
\text { yrs }\end{array}$ \\
\hline A & Pregnancy & High & $97-144$ & $44(59 \%)$ \\
& & Average & $49-96$ & $28(37 \%)$ \\
\hline \multirow{2}{*}{ B } & \multirow{2}{*}{$\begin{array}{l}\text { Maternal \& Child Services } \\
\text { \&programmes }\end{array}$} & Low & $<48$ & $3(4 \%)$ \\
& High & $67-99$ & $42(56 \%)$ \\
\cline { 3 - 5 } & Average & $34-66$ & $27(36 \%)$ \\
\hline C & General & Low & $<33$ & $6(8 \%)$ \\
\hline & & High & $27-39$ & $44(59 \%)$ \\
\hline & & Average & $14-26$ & $28(37 \%)$ \\
\hline & Low & $<13$ & $3(4 \%)$ \\
\hline
\end{tabular}


Table.3 Occupation wise distribution of the selected sample ( $\mathrm{N}=75)$

\begin{tabular}{|c|c|c|c|}
\hline $\begin{array}{l}\text { House } \\
\text { wife } \\
\text { N \& \% }\end{array}$ & $\begin{array}{l}\text { Fully } \\
\text { involved in } \\
\text { agriculture } \\
N \& \%\end{array}$ & $\begin{array}{l}\text { Partially } \\
\text { involved in } \\
\text { agriculture } \\
\text { N \& \% }\end{array}$ & $\begin{array}{l}\text { Petit } \\
\text { business } \\
\text { N \& \% }\end{array}$ \\
\hline $9(12 \%)$ & $33(44 \%)$ & $28(37 \%)$ & $5(7 \%)$ \\
\hline
\end{tabular}

Table.7 Maternal and child health awareness scores (Pre \& Post) of rural mothers women with children $(2-5 \mathrm{yrs})(\mathrm{N}=75)$

\begin{tabular}{|c|c|c|c|c|c|c|c|c|c|}
\hline \multirow[t]{2}{*}{ Dimensions } & \multirow{2}{*}{$\begin{array}{l}\text { Sub- } \\
\text { Dimensions }\end{array}$} & \multicolumn{2}{|c|}{ Raw scores } & \multicolumn{2}{|c|}{ Mean } & \multicolumn{2}{|c|}{ SD } & \multirow{2}{*}{$\begin{array}{c}\text { Mean } \\
\text { differences } \\
\text { (P1-P) }\end{array}$} & \multirow{2}{*}{$\begin{array}{c}\mathrm{T} \\
\text { values }\end{array}$} \\
\hline & & (P) & (P1) & (P) & (P1) & (P) & (P1) & & \\
\hline \multirow{8}{*}{$\begin{array}{l}\text { A. Pregnancy } \\
\text { (48 statements) }\end{array}$} & A & 695 & 747 & 9.27 & 9.96 & 2.26 & 3.06 & 0.69 & $0.04 \mathrm{NS}$ \\
\hline & B & 933 & 1101 & 12.44 & 14.68 & 3.46 & 5.36 & 2.24 & $7.18 * *$ \\
\hline & C & 550 & 673 & 7.33 & 8.97 & 2.41 & 3.59 & 1.64 & $1.24 * *$ \\
\hline & D & 583 & 698 & 7.77 & 9.31 & 2.64 & 3.68 & 1.54 & $5.31^{* *}$ \\
\hline & $\mathbf{E}$ & 1419 & 1752 & 18.92 & 23.36 & 6.78 & 6.46 & 4.44 & $5.05 * *$ \\
\hline & $\mathbf{F}$ & 787 & 962 & 10.49 & 12.83 & 3.70 & 3.41 & 2.34 & $2.95 * *$ \\
\hline & G & 511 & 630 & 6.81 & 8.4 & 2.66 & 2.57 & 1.59 & $2.19^{* *}$ \\
\hline & Total & 5478 & 6563 & 73.04 & 87.51 & 20.98 & 24.84 & 14.47 & $5.2^{* * *}$ \\
\hline \multirow{7}{*}{$\begin{array}{l}\text { B: Maternal \& } \\
\text { Child Services } \\
\text { and } \\
\text { programmes( } 33 \\
\text { statements) }\end{array}$} & $\mathbf{A}$ & 526 & 573 & 7.01 & 7.64 & 2.38 & 3.08 & 0.63 & $0.02 \mathrm{NS}$ \\
\hline & B & 640 & 770 & 8.53 & 10.27 & 3.07 & 4.00 & 1.74 & $0.01 \mathrm{NS}$ \\
\hline & C & 596 & 752 & 7.95 & 10.03 & 2.67 & 3.42 & 2.08 & $1.49^{* *}$ \\
\hline & D & 1059 & 1268 & 14.12 & 16.91 & 4.88 & 4.74 & 2.79 & $2.35^{* *}$ \\
\hline & $\mathbf{E}$ & 696 & 808 & 9.28 & 10.77 & 3.0 & 3.14 & 1.19 & $9.01 * *$ \\
\hline & $\mathbf{F}$ & 566 & 671 & 7.55 & 8.95 & 2.59 & 2.65 & 1.4 & $7.95 * *$ \\
\hline & Total & 4083 & 4842 & 54.44 & 64.56 & 15.78 & 17.90 & 10.12 & $4.34 * *$ \\
\hline \multirow{4}{*}{$\begin{array}{l}\text { C: General (13 } \\
\text { statements) }\end{array}$} & A & 459 & 581 & 6.12 & 7.75 & 1.80 & 1.97 & 1.63 & $1.32 * *$ \\
\hline & B & 381 & 468 & 5.08 & 6.24 & 1.84 & 1.63 & 1.16 & $9.9^{* *}$ \\
\hline & C & 842 & 978 & 11.23 & 13.04 & 4.04 & 3.46 & 1.81 & $1.43 * *$ \\
\hline & Total & 1682 & 2027 & 22.43 & 27.03 & 6.51 & 5.87 & 4.6 & $1.72 * *$ \\
\hline
\end{tabular}

Note: $* *$ at $1 \%$ level of significance

Abbreviations

\begin{tabular}{|l|l|l|}
\hline 1. Pregnancy & $\begin{array}{l}\text { 2.Maternal \& Child health } \\
\text { Services \&programmes }\end{array}$ & 3. General \\
\hline A: Signs of Pregnancy & $\begin{array}{l}\text { A: Reproductive \& child health } \\
\text { programmes }\end{array}$ & $\begin{array}{l}\text { A: Practices that jeopardize infant } \\
\text { health, growth or survival }\end{array}$ \\
\hline B: Care during Pregnancy & B: Purpose of R \& CH & B: Care of the new born \\
\hline C: Factors affecting healthy & C: Antenatal care services & C: Nutritional care of the child \\
\hline D: Health aspects of pregnancy & D: Purpose of Antenatal care & \\
\hline E: Danger signs of pregnancy & E: Postnatal care services & \\
\hline F: Complications during & F: Purpose of Postnatal care & \\
\hline G: Types of Delivery & & \\
\hline
\end{tabular}



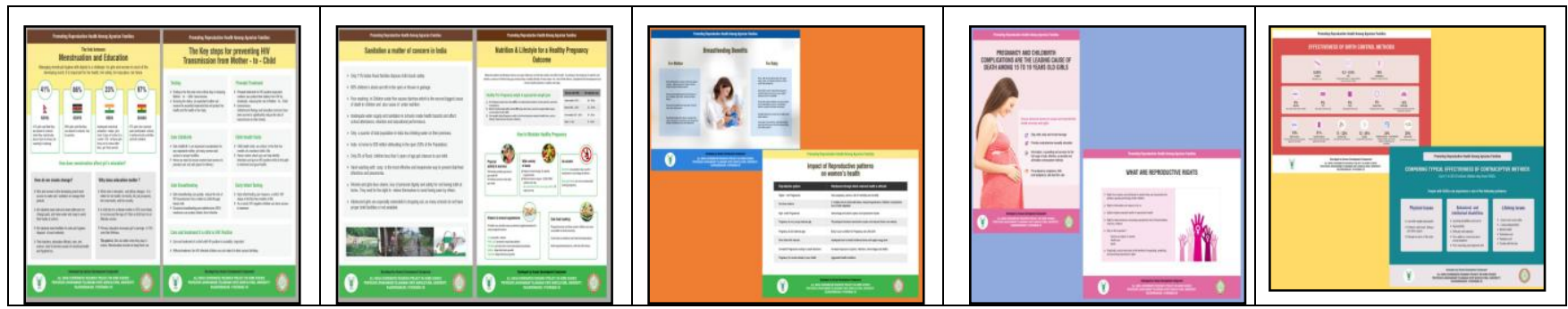

\section{Capacity building programmes}

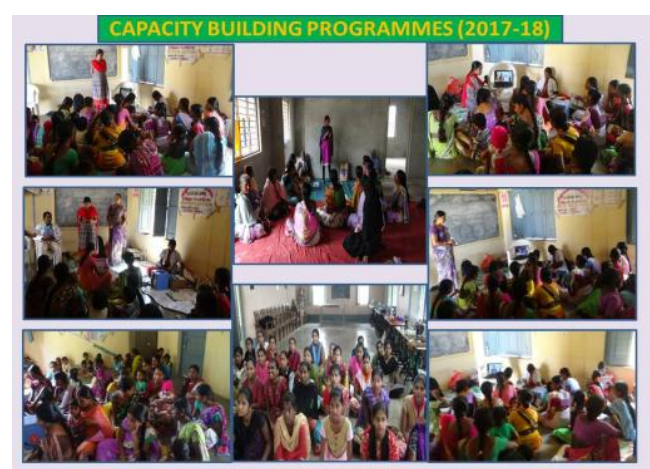

Reproductive Health knowledge scores of Married women (without children) - Dimension $\&$ category wise

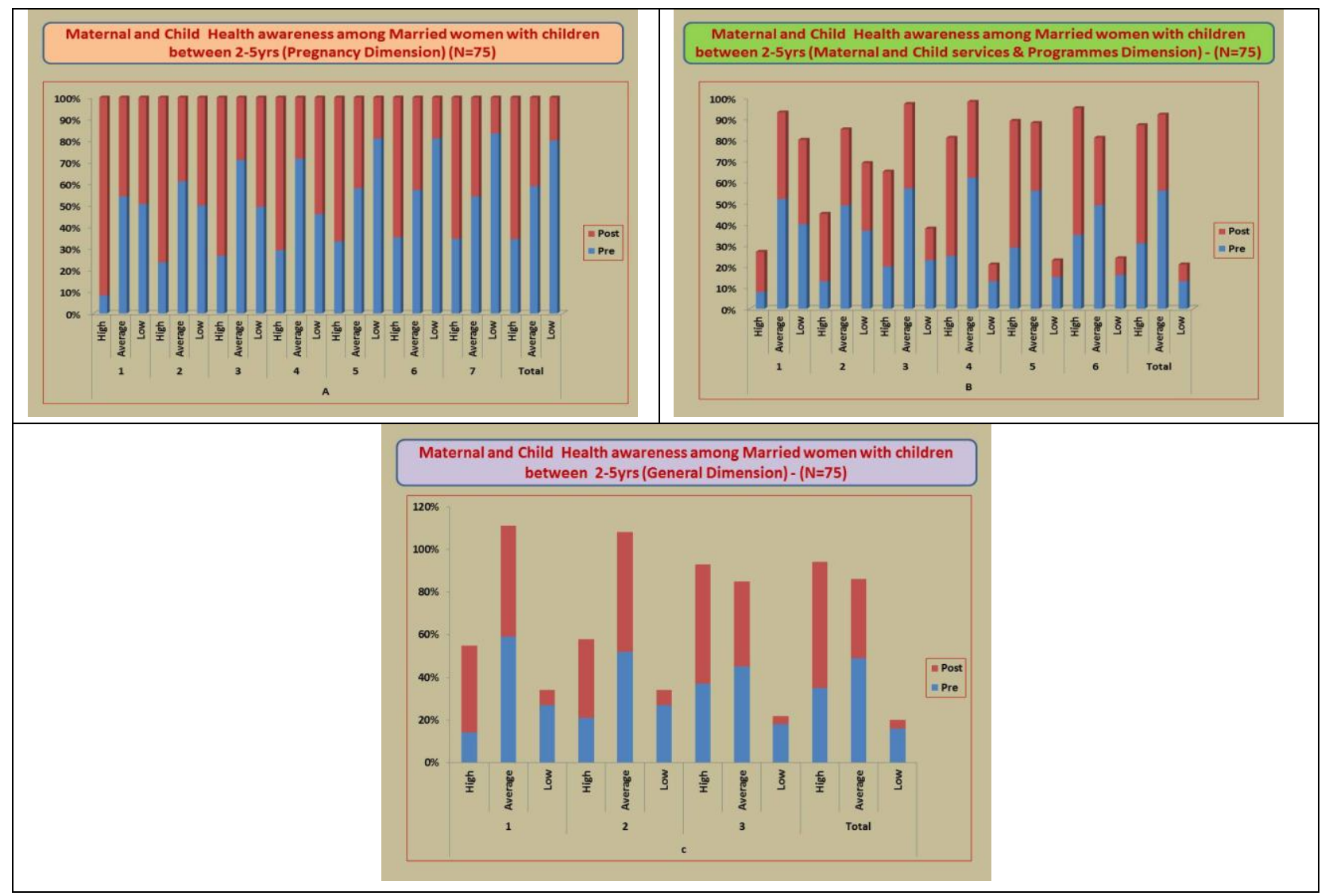




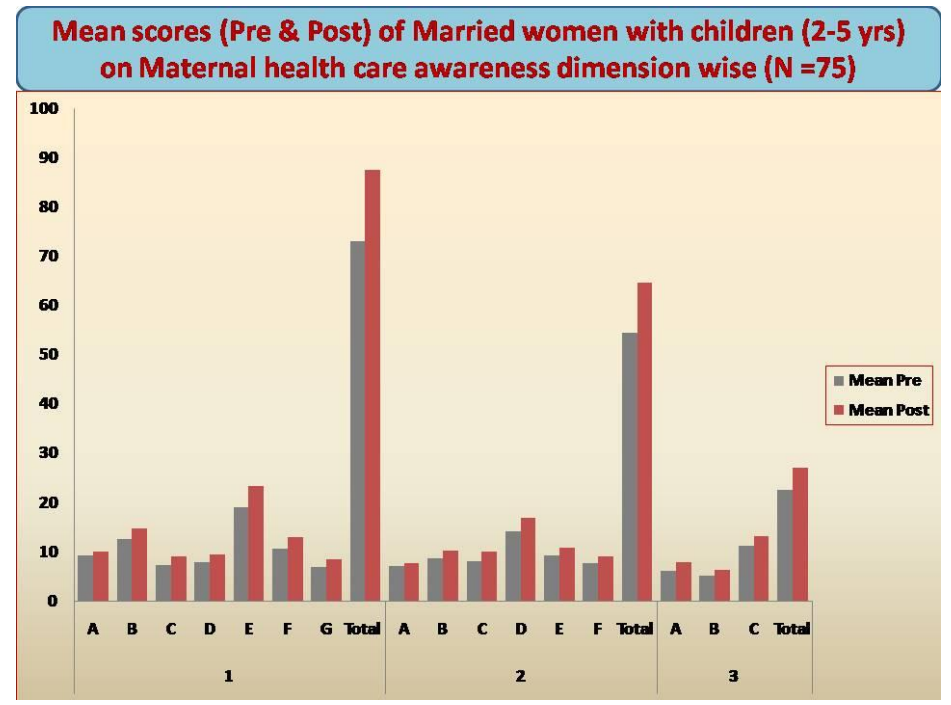

The table 7 presents the Pre \& Posttest (Raw scores, Means, SD and T values) Scores of Married women (with children between 2-5 yrs) with regard to Sub-dimensions under Maternal Health and Child Care.

The table shows the progressive increase in the total raw scores across pre-test to posttest, along with the increase in the mean differences, which shows the impact of intervention programme.

$\mathrm{T}$ values between the two means of pre-test and post-test was found to be highly significant, as the calculated values were found to be greater than the tabulated value. The results reflect the effectiveness of Intervention programmes on the Knowledge levels of Married women with reference to Reproductive Health.

In conclusion, maternal health care services should focus on ensuring there is continuum of care through strengthening the health system and provision of good quality of health care in a well organized referral health system from community level to high facility levels. It is important to ensure that health facilities are well equipped with required mix of skilled personnel, essential drugs and simple standard equipment with availability of reliable transport to attend emergency services in case there is a need for referral to high level facilities.

Specific strategies should be in place to empower women, men and community members at large which are complemented with adequate health information for them to make informed decision of issues affecting health and family.

\section{Acknowledgement}

The present study was supported by ICAR under XIII plan period

\section{References}

AbouZahr, C., Wardlaw, T., Stanton, C. and Hill, K. (1995) Maternal mortality. World Health Statistics Quarterly 49, 77-87.

Campbell, O.M. (2006) Strategies for reducing maternal mortality: getting on with what works. www.ncbi.nlm.nih. gov/pubmed/17027735.

FHI (2007) Safe Motherhood: A Review 1987-2005. Family Health International $4,78-82$. 
Koblinky, M.A. (2003) Reducing Maternal Mortality: Learning from Bolivia, China, Egypt, Honduras,Indonesia, Jamaica and Zimbabwe. The World Bank, Human Development Network.

Rogo, K.O., Ouch, J. and Mwalali, P. (2006) Maternal Mortality: Disease and Mortality in Sub-SaharanAfrica.2nd edition.World Bank, Washington DC.http://www.ncbi.nlm.nih.gov/pubme d/21290649
Urassa, E., Lindmark, G. \& Nystrom, L. (1995) Maternal mortality in Dar es Salaam, Tanzania: Socioeconomics, obstetric history and case accessibility of health care factors. African Journal ofHealth Sciences 2, 242-249.

Waldijk, K. (1994) Surgeons show success in early fistula repairs. Safe Motherhood Newsletter, Issue 14, March-June 1994.

WHO/UNICEF/UNPF/ World Bank (2005) Maternal Mortality in 2005..World Health Organization, Geneva.

\section{How to cite this article:}

Nasreen Banu and Yashoda, K. 2018. Impact of Intervention on Maternal and Child Health Knowledge of Farm Mothers. Int.J.Curr.Microbiol.App.Sci. 7(11): 1947-1956. doi: https://doi.org/10.20546/ijcmas.2018.711.221 